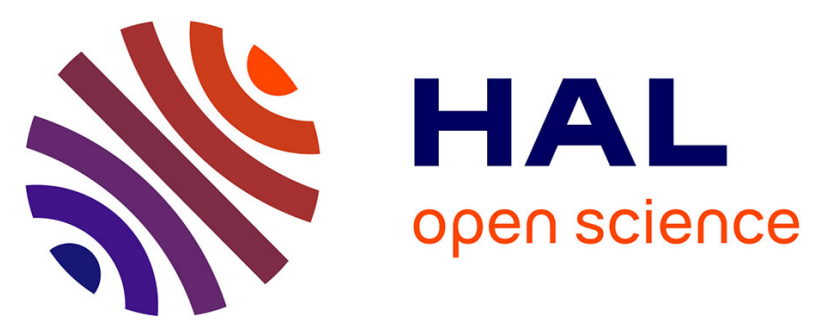

\title{
Compositional Effects on Morphology, Structure and Superconducting Properties of YxBay CuzO7- $\delta$ Thin Films Prepared by Metalorganic Chemical Vapour Deposition
}

\author{
M. Doudkowsky, J. Santiso, A. Figueras, R. Berjoan
}

\section{To cite this version:}

M. Doudkowsky, J. Santiso, A. Figueras, R. Berjoan. Compositional Effects on Morphology, Structure and Superconducting Properties of YxBay CuzO7- $\delta$ Thin Films Prepared by Metalorganic Chemical Vapour Deposition. Journal de Physique IV Proceedings, 1995, 05 (C5), pp.C5-415-C5-422. 10.1051/jphyscol:1995548 . jpa-00253910

\author{
HAL Id: jpa-00253910 \\ https://hal.science/jpa-00253910
}

Submitted on 1 Jan 1995

HAL is a multi-disciplinary open access archive for the deposit and dissemination of scientific research documents, whether they are published or not. The documents may come from teaching and research institutions in France or abroad, or from public or private research centers.
L'archive ouverte pluridisciplinaire $\mathbf{H A L}$, est destinée au dépôt et à la diffusion de documents scientifiques de niveau recherche, publiés ou non, émanant des établissements d'enseignement et de recherche français ou étrangers, des laboratoires publics ou privés. 


\title{
Compositional Effects on Morphology, Structure and Superconducting Properties of $\mathbf{Y}_{x} \mathrm{Ba}_{y} \mathrm{Cu}_{z} \mathrm{O}_{7-\delta}$ Thin Films Prepared by Metalorganic Chemical Vapour Deposition
}

\author{
M. Doudkowsky, J. Santiso, A. Figueras and R. Berjoan* \\ Institut de Ciència de Materials de Barcelona CSIC, Campus UAB, 08193 Bellaterra, Spain \\ * Institut de Science et de Génie des Matériaux et des Procédés, CNRS, BP. 5, Odeillo, 68120 Font \\ Romeu, France
}

\begin{abstract}
In this paper we report the preparation of quasi-stoichiometric layers (Ba -deficient and Ba-rich) by MOCVD. The compositional effects on the morphology, structure and superconducting properties were studied too.
\end{abstract}

\section{INTRODUCTION}

Many groups [1] have demonstrated that the morphology, microstructure and superconducting properties of $\mathrm{YBa}_{2} \mathrm{Cu}_{3} \mathrm{O}_{7-\delta}(\mathrm{YBCO})$ thin films depend on the composition of $\mathrm{Y}, \mathrm{Ba}, \mathrm{Cu}$ and $\mathrm{O}$. Zhao et al. [2] have proved that optimal $j_{c}$, in $Y B C O$ layers, was obtained for compositions $\mathrm{Ba} / \mathrm{Y}=1.6$ and $\mathrm{Cu} / \mathrm{Y}=5$ which are very far from the "123" stoichiometry. In this case, the surface morphology was not flat. On the contrary, Hudner et al.[3] got flat surfaces in $\mathrm{YBCO}$ layers with a composition evaluated in $\mathrm{Ba} / \mathrm{Y}=1.5$ and $\mathrm{Cu} / \mathrm{Ba}=$ 1.9 (Ba deficient layers) and with a critical current density $\mathrm{j}_{\mathrm{c}}=3.10^{6} \mathrm{~A} / \mathrm{cm}^{2}$. It should also be noted that films prepared by CVD demonstrated excellent behaviour in the presence of magnetic field. The pinning mechanisms wich induce high critical current densities are poorly understood. However, some authors [4] suggested that $\mathrm{Y}_{2} \mathrm{O}_{3}$ nanoprecipitates act as active flux pinning centers when the applied field is perpendicular to $\mathrm{CuO}_{2}$ planes.

From these antecedents, it should be concluded that the control of the morphology and composition of the deposits is a revelant fact which can be achieved in MOCVD, mainly, by the control of the composition of the gas phase and the deposition temperature. The evaporation temperature of the precursors and substrate temperature are two of the more important technological parameters which control the concentration of the precursors in the gas phase and the deposition yield of the $\mathrm{Y}, \mathrm{Ba}$ and $\mathrm{Cu}$, respectively.

This paper deals with the study of the variation of the morphology and superconducting properties in quasi-stoichiometric and off-stoichiometry layers prepared by MOCVD. It should be noted that in Ba deficient layers yttria nanoprecipitates, that could act as pinning center, are incorporated into the YBCO matrix [5].

In this context, it will be discussed as well, the best experimental conditions for preparing YBCO layers with smooth surfaces (indispensable for electronic applications) and the influence of the Ba concentation on the critical temperature $\left(\mathrm{T}_{\mathrm{c}}\right)$ of the superconducting films. 


\section{EXPERIMENTAL}

The films were grown by MOCVD on differents substrates $\left(\mathrm{SrTiO}_{3}, \mathrm{YSZ}, \mathrm{MgO}\right)$ in a horizontal hot-wall reactor.The $\beta$-diketonates: $\mathrm{Y}$ (thd) ${ }_{3}, \mathrm{Cu}$ (thd $)_{2}$ and $\mathrm{Ba}(\text { thd })_{2}$ were used as organometallic precursors. The study of the chemical composition of the deposits as the function of the deposition temperature ( $\mathrm{T}_{\text {sub }}$ ) was performed by means of the layers prepared at $\mathrm{T}_{\text {sub }}$ ranged between $700^{\circ} \mathrm{C}$ and $825^{\circ} \mathrm{C}$.

The total pressure in the reactor was 10 Torr. The thickness of the layers was ranged between 200 and $500 \mathrm{~nm}$.

The off-stoichiometric films were obtained at standard experimental conditions [6] althought the evaporation temperature of the Ba-precursor changes from 210 to $214^{\circ} \mathrm{C}$. These layers show different $\mathrm{Ba}$ content, varing from $\mathrm{Ba} / \mathrm{Y}=1.5$ (Ba-deficient) to $\mathrm{Ba} / \mathrm{Y}=2.5$ (Ba-rich). The $\mathrm{Cu} / \mathrm{Y}$ ratio was held in a quasi-stoichiometric range of $3 \pm 0.2$.

The chemical composition and structure of the layers were obtained by electron microprobe analysis and X-ray diffraction, respectively. Superconducting properties of the films were measured by ACsusceptometer and SQUID.

\section{RESULTS AND DISCUSSION}

3.1 Dependence of the composition on $T_{s u b}$ Deposition temperature is a revelant technological parameter in the control of the stoichiometry of the deposited layers because the deposition yield of the $\mathrm{Cu}, \mathrm{Ba}$ and $\mathrm{Y}$ depends on this temperature. Figure 1 shows the evolution of the ratio between the deposited and evapored molar fraction of $\mathrm{Cu} / \mathrm{Y}$ and $\mathrm{Ba} / \mathrm{Y}$ as a function of the substrate temperature. These dependences have been obtained from layers grown on different substrates $\left(\mathrm{SrTiO}_{3}, \mathrm{MgO}, \mathrm{NdGaO}\right.$ and $\left.\mathrm{YSZ}\right)$.

As a general trend, it can be concluded that in our experimental set up the $\mathrm{Cu}$ efficiency in the deposition is higher than the $Y$ while the Ba yield is less than the $Y$ one. It should be also observed that the efficiency in the deposition of the $\mathrm{Ba} / \mathrm{Y}$ is held constant in the range of $\mathrm{T}_{\text {sub }}=700-820^{\circ} \mathrm{C}$ while $\mathrm{Cu} / \mathrm{Y}$ increases from 1.5 to 3 . Consequently, at $820^{\circ} \mathrm{C}$, the incorporation of the $\mathrm{Cu}$ into the layer is twice with respect to $700^{\circ} \mathrm{C}$, providing the same Cu evaporated mass.

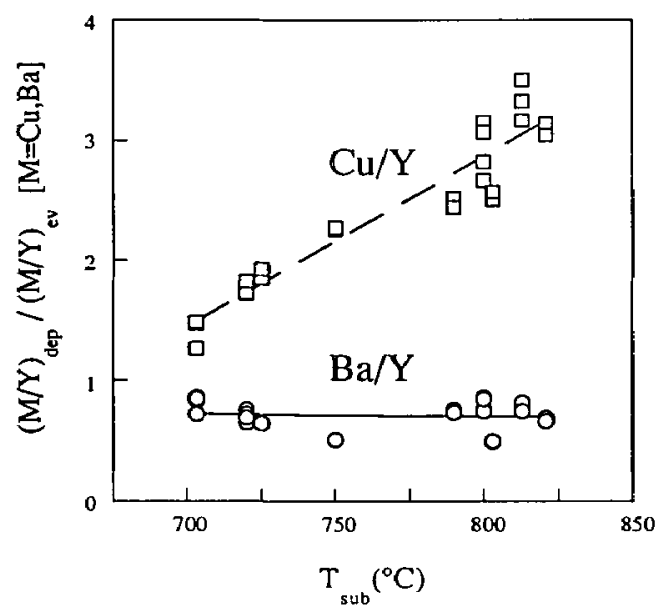

Figure 1: Evolution of the deposition yield $(\mathrm{M} / \mathrm{Y})_{\mathrm{dep}} /(\mathrm{M} / \mathrm{Y})_{\mathrm{ev}}[\mathrm{M}=\mathrm{Cu}, \mathrm{Ba}]$ with the substrate temperature 


\subsection{Structure of quasi-stoichiometric layers}

Figure 2 shows the X-ray diffractogram of YBCO layers deposited on $\mathrm{SrTiO}_{3}(100)$ at three different temperatures. At lower $\mathrm{T}_{\text {sub }}=650^{\circ} \mathrm{C}$, the film exhibits a majority preferential orientation along the a-axis wich is perpendicular to the surface of the substrate. When $T_{\text {sub increases, the preferential orientation }}$ changes gradually from a-axis to c-axis orientation. The morphology exhibited by the layers was discussed elsewhere [7]. Layers prepared at $800^{\circ} \mathrm{C}$ exhibit a high c-axis orientation with a mean value in the FWHM (005) rocking curve of $0.5^{\circ}$. Their texture was studied by means of the (104)-YBCO pole figure. This reflection was chosen because is off-plane and it does not overlap with someone coming from the substrate. The pole figure shows four spots indicating a four fold-symmetry with respect the c-axis. The domains are aligned with the principal directions of the substrate and they appear rotated $90^{\circ}$ around the $\mathrm{c}$-axis [001]. The critical temperature of these films was $T_{c}$ (onset) $=91.5 \mathrm{~K}$ and the critical current density $\mathrm{j}_{\mathrm{c}}=10^{6} \mathrm{~A} / \mathrm{cm}^{2}(77 \mathrm{~K}, 0 \mathrm{~T})$.

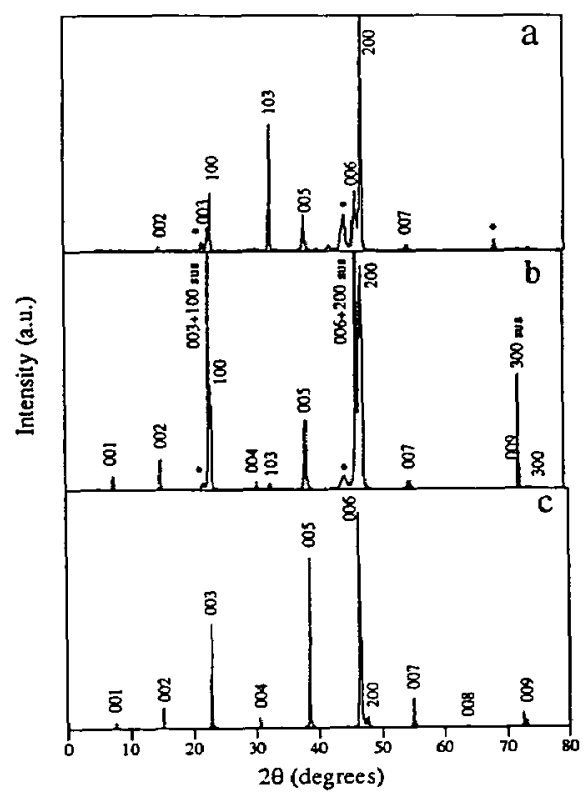

Iigure2: X-ray diffractograms of YBCO layers deposited at (a) $\mathrm{T}_{\text {sub }}=650^{\circ} \mathrm{C}$, (b) $\mathrm{T}_{\text {sub }}=725^{\circ} \mathrm{C}$, (c) $\mathrm{T}_{\text {sub }}=800^{\circ} \mathrm{C}$ 
3.3 Morphology and superconducting properties of off-stoichiometry layers Off-stoichiometric layers deposited on $\mathrm{SrTiO}_{3}(100)$ were obtained at $\mathrm{T}_{\text {sub }}=800^{\circ} \mathrm{C}$ in order to induce a preferential orientation along the c-axis

\section{3.l Morphology of off-stoichiometric layers}

Figure 3 collects the evolution of the surface morphology of the layers with the concentration of $\mathrm{Ba}$. The density, shape and size of the microprecipitates change when the layers reach the zone of stoichiometry "123". For Ba-concentration below the stoichiometry, $\mathrm{Y}_{2} \mathrm{O}_{3}$ and $\mathrm{Y}_{2} \mathrm{Cu}_{2} \mathrm{O}_{5}$ precipitates were identified in the layers. The yttria precipitates were detected by $X$-ray diffraction $\left(2 \theta=34^{\circ}\right.$ identified as the $(004)$ reflection of cubic $\mathrm{Y}_{2} \mathrm{O}_{3}$ ). These precipitates did not appear in the surface suggesting that the excess of $\mathrm{Y}$ is incorporated into the layers. On the contrary, for Ba-concentration above the stoichiometric concentration, barium carbonate and $\mathrm{BaCuO}_{5}$ precipitates were obtained.

Figure 4a shows the surface morphology of the layer obtained at $\mathrm{T}_{\text {sub }}=800^{\circ} \mathrm{C}$ with a composition $\mathrm{Cu} / \mathrm{Y}=3.7$ and $\mathrm{Ba} / \mathrm{Y}=1.8$ (Ba deficient layer). The evaporation temperature of $\mathrm{Y}, \mathrm{Ba}$ and $\mathrm{Cu}$ precursors were: $\mathrm{T}_{\mathrm{Y}}=117^{\circ} \mathrm{C}, \mathrm{T}_{\mathrm{Ba}}=212^{\circ} \mathrm{C}$ and $\mathrm{T}_{\mathrm{Cu}}=103^{\circ} \mathrm{C}$. The substrate was $\mathrm{SrTiO}_{3}(100)$. It should be noted that the surface was rough with the presence of precipitates identified mostly as $\mathrm{Y}_{2} \mathrm{Cu}_{2} \mathrm{O}_{5}$. The critical temperature measured by an $\mathrm{AC}$ susceptometer was $\mathrm{T}_{\mathrm{C}}$ (onset) $=83 \mathrm{~K}$.

The result showed at figure 1 suggested that $\mathrm{Cu}$ and $\mathrm{Y}$ excess in the layers could be reduced by decreasing the deposition temperature. These reasons induced to carry out deposits at $700^{\circ} \mathrm{C}$ without any change in the composition of the gas phase. Figure $4 \mathrm{~b}$ displays the surface morphology of a layer obtained at these conditions. The films were quasi-stoichiometric $(\mathrm{Cu} / \mathrm{Y}=2.8, \mathrm{Ba} / \mathrm{Y}=1.85)$ and the density of microprecipitates was very small leading to almost flat surfaces. The Cu excess was eliminated because the different efficiency in the incorporation of this cation to the layer, besides $\mathrm{Ba} / \mathrm{Y}$ ratio is maintened when the deposition temperature decreases, as predicted in figure 1. XRD analysis permitted to evaluate in 70 the percentage of volume which correspond to the c-axis domains in the deposit. The critical temperature of th film was $T_{c}=88 \mathrm{~K}$.

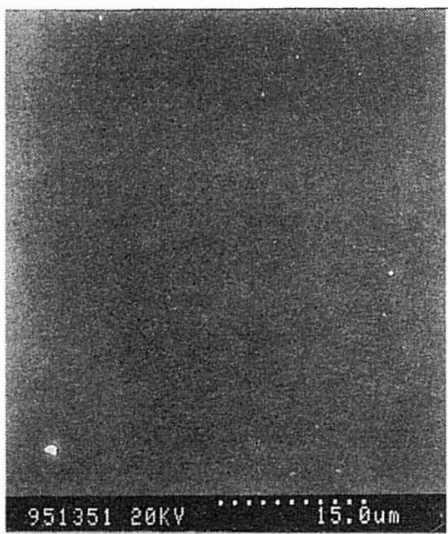

(a)

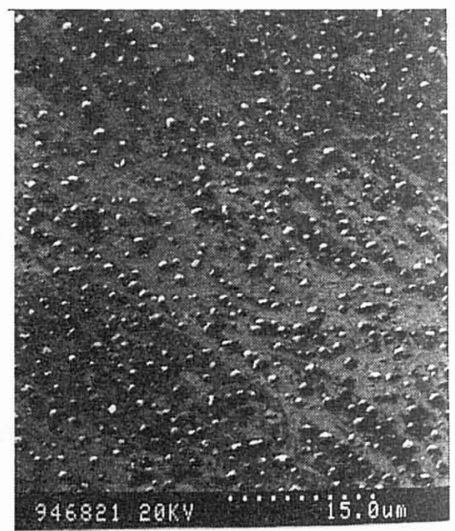

(b)

Figure 3: SEM micrographs showing the morphology of the layers prepared at $\mathrm{Cu} / \mathrm{Y}=3 \pm 0.2$. Ba concentration varies from $\mathrm{Ba} / \mathrm{Y}=1.8$ (a) to $2.3(\mathrm{~b})$. 


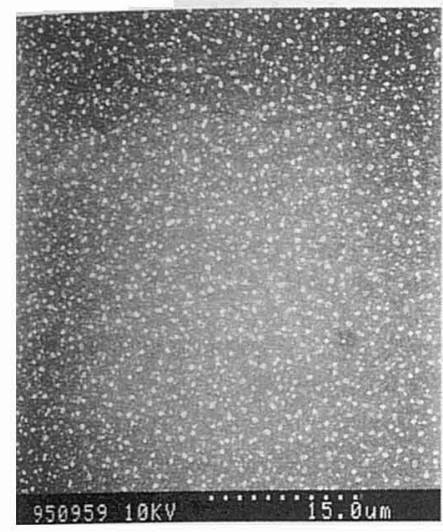

(a)

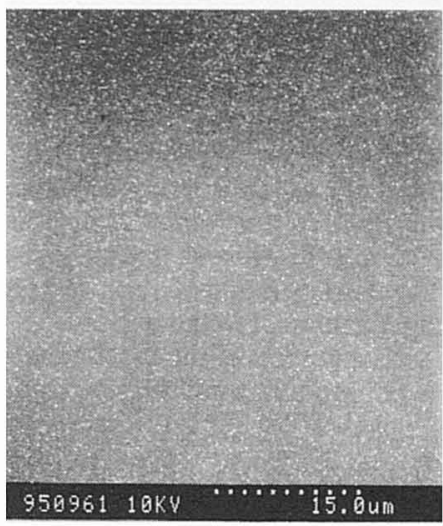

(b)

Figure 4: SEM micrographs corresponding to (a) off-stoichiometric layer: rough surface, (b) quasi-stoichiometric deposit: flat surface.

\subsubsection{Superconducting properties of off stoichiometric layers}

Figure 5 indicates the variation of $\mathrm{T}_{\mathrm{c}}$ as a function of the ratio $\mathrm{Ba} / \mathrm{Y}$ when $\mathrm{Cu} / \mathrm{Y}$ ratio is held at $3 \pm 0.2$. The evolution essentially agrees with the results published by Zhao et al. which correspond to films prepared by PEMOCVD [2]. The highest critical temperature was obtained at $\mathrm{Ba} / \mathrm{Y}$ ratio of 1.9 which does correspond with the stoichiometric one.

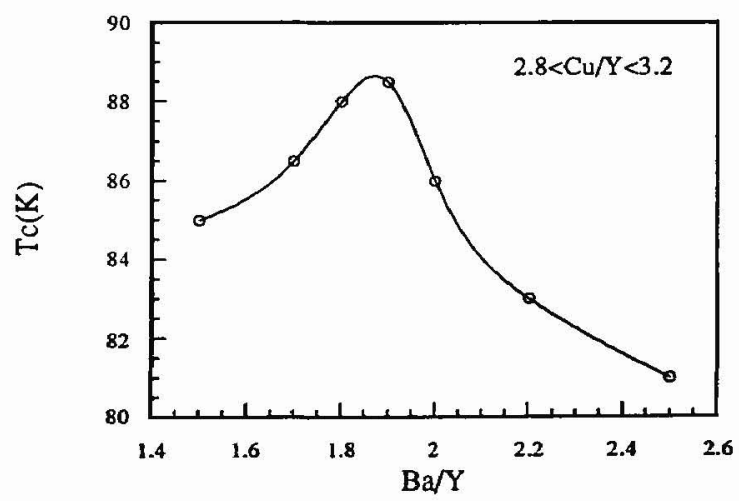

figure 5: Dependence of the critical temperature with the ratio $\mathrm{Ba} / \mathrm{Y}$ in highly $\mathrm{c}$-axis oriented $\mathrm{YBCO}$. 
The evolution of the critical temperature (up to $\mathrm{Ba} / \mathrm{Y}=1.9$ ) cannot be correlated with variations in the oxygen concentration of the layers. Figure 6 shows the dependence of c-lattice parameter with the ratio of $\mathrm{Ba} / \mathrm{Y}$. The value of $\mathrm{c}$ is close to $11.67 \pm 0.01 \AA$ indicating that the films are fully oxygenated. It should be pointed out that quasi-stoichiometric layers $(\mathrm{Ba} / \mathrm{Y}=2)$ were further annealed in pure oxygen at temperature of $480^{\circ} \mathrm{C}$, no variations in the values of $\mathrm{c}$ parameter and consequently, in its $\mathrm{T}_{\mathrm{c}}$ were detected. These facts suggest that our value of the c parameter correspond to layers fully oxygenated and thus, the evolution of $T_{c}$ versus $B a / Y$ is not related with the oxygene content of the films. Above $B a / Y=1.9$, the value of $c$ increases while $T_{\mathfrak{c}}$ decreases strongly. An explanation of this fact have been proposed by Matijasevic et al.[8]. The enlargement of the c parmeter is due to the substitution, in the unit cell, of $\mathrm{Y}$ by $\mathrm{Ba}$ with increasing Ba content in the deposit.

The determination of the mechanism of the $c$ enlargement and the reasons of the evolution of the $T_{c}$ on the $\mathrm{Ba} / \mathrm{Y}$ ratio requires an accurated study of off-stoichiometric samples which is underway.

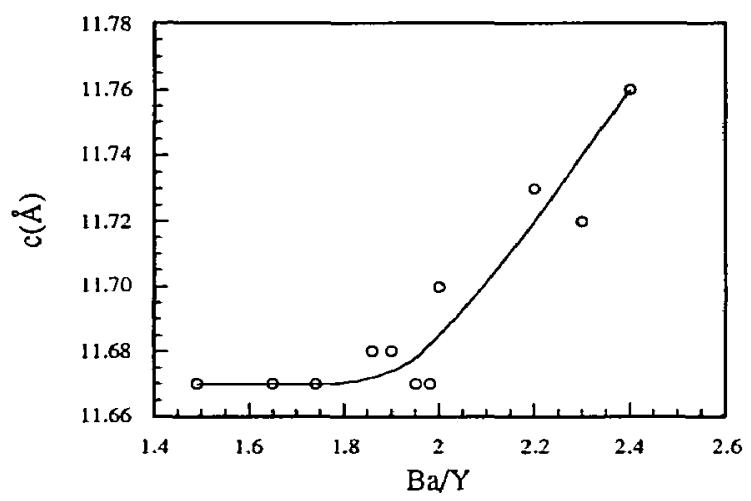

Figure 6: Dependence of the $\mathrm{c}$ parameter with the ratio $\mathrm{Ba} / \mathrm{Y}$ in $\mathrm{c}$-axis oriented $\mathrm{YBCO}$ layers.

Figure 7 shows the dependence at $5 \mathrm{~K}$ of $\mathrm{j}_{\mathrm{c}}$ with a magnetic field, applied perpendicular to the $\mathrm{CuO}_{2}$ planes (in our case, these planes are parallel to the substrate). Sample a corresponds to quasistoichiometric layer while sample $b$ is off-stoichiometric film with $\mathrm{Ba} / \mathrm{Y}$ ratio of 1.8 and $\mathrm{Cu} / \mathrm{Y}$ of 2.8 . The critical current densities decrease from $410^{6}$ to $510^{5} \mathrm{~A} / \mathrm{cm}^{2}$ at $5 \mathrm{~T}$ (sample a) and from $1.210^{7}$ to $510^{5}$ $\mathrm{A} / \mathrm{cm}^{2}$ at $5 \mathrm{~T}$ (sample b). The yttria precipitates detected in Ba-deficient layers seem to act, below $1 \mathrm{~T}$, as pinning centers [9] enhaning the critical current density from $410^{6}$ (quasi- stoichiometric layers) to 1.2 $10^{7} \mathrm{~A} / \mathrm{cm}^{2}$ at $\mathrm{B}=0 \mathrm{~T}$. At high magnetic field the dependence of $\mathrm{j}_{\mathrm{c}}$ is similar for both layers, indicating that the mecanism of pinning is independent of the concentration of yttria precipitates and second phases and probably depends on the intrinsic quality of the material (density of dislocations...).

It must be remembered that both samples have similar orientation, essentially the same density of twins and a-oriented domains but different densities of $\mathrm{Y}_{2} \mathrm{O}_{3}$ and second phases. At this moment is difficult to elucidate exactly the mecanism of pinning but there is a correlation between the non-stoichiometry in the layers and the behaviour of $j_{c}$ with respect to the magnetic field. Accurated texture, microstructure and transport characterizations must be carried out in order to elucidate univocally the pinning mechanisms at low and high magnetic field. 


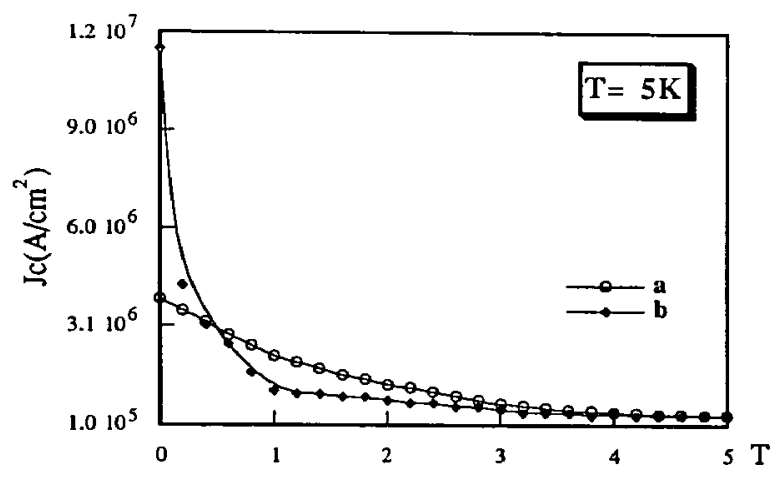

Figure 7: Dependence of $\mathrm{j}_{\mathrm{c}}$ with an external magnetic field, parallel to YBCO c-axis, measured in two samples, (a) quasistoichiometric, (b) Ba-deficient.

\section{CONCLUSIONS}

1.- The efficiency of the deposition of $\mathrm{Cu}, \mathrm{Ba}$ and $\mathrm{Y}$ depends on the deposition temperature. This fact can be used for elimination of $\mathrm{Cu}$ and $\mathrm{Y}$-rich microprecipitates in Ba-deficient layers by decreasing the deposition temperature. Flat surface, precipitates free and quasi-stoichiometric c-oriented layers can be prepared for technological applications.

2.- The influence of $\mathrm{Ba}$ content on properties such as morphology, structure and superconducting properties was studied by means of off-stoichiometric layers prepared by varing the evaporation temperature of the $\mathrm{Ba}$ precursor between $210^{\circ} \mathrm{C}$ and $214^{\circ} \mathrm{C}$. The critical temperature shows a dependence with the $\mathrm{Ba} / \mathrm{Y}$ ratio. This evolution is not correlated with a change in the oxygen content in the films (for $\mathrm{Ba} / \mathrm{Y}<1.9$ ) because in all this range the $\mathrm{c}$ parameter correspond to a fully oxygenated layer. The enlargement of the $\mathrm{c}$ parameter above the quasi stoichiometric composition ( $\mathrm{Ba} / \mathrm{Y}>1.9$ ) could be attributed to a substitution of $\mathrm{Y}$ by $\mathrm{Ba}$ with increasing $\mathrm{Ba}$ content.

3.- Ba deficient layers show precipitates that seem to act as pinning centers at low magnetic field (1T). At higher values, mechanisms related with the intrinsic quality of the material seem to control the mechanism of pinning.

\section{Acknowledgements}

The authors thank Mr X. Llovet and L. Balo for carrying out some of the work and Dr J. Fontcuberta and B. Martinez for helpful discussions. This work was partially suported by CICYT project MAT468/92. 


\section{References}

[1]Li Y.Q., Zhao J., Chern C.S., Lu P., Gallois B., Norris P., Kear B., Cosendey F., Physica C 195 (1992) 161.

[2]Zhao J., Norris P., Thin solid films 206 (1991) 122.

[3]Hudner J., Thomas O., Mossang E., Chaudouet P., Weiss F., Boursier D., Senateur J.P., J. Appl. Phys. 74 (1993) 4631.

[4]Li Y.Q., Zhao J., Chern C.S., Lu P., Chien T.R., Gallois B., Norris P., Kear B., Cosendey F., Appl. Phys. Lett. 60 (19) (1992) 2430.

[5]Santiso J., Figueras A., Schamm S., Grigis C., Dorignac D., Sevely J., Physica C 235-240 (1994) 619.

[6]Santiso J., Figueras A., J. Physique IV C3 (1993) 353.

[7]Schulte B., Maul M., Haüsler P., Adrian H.A., Appl. Phys. Lett. 62 (6) (1993) 633.

[8]Matijasevic V.C., Rosenthal P., Hammond R.H., Beasley M.R., Shinoara K., Physics and Material Science of High Temperature Superconductors, (R. Kossowsky, B. Raveau, D. Wohlleben, S. K. Patapis, Kluwer Academic, Dordrecht, Netherlands, 1992) pp.557.

[9]Hirai T., Yamane H., J. Cryst. Growth 107(1991) 683. 